\title{
Tachykinins and neurokinin receptors in bone marrow functions: neural-hematopoietic link
}

This article was published in the following Dove Press journal:

Journal of Receptor, Ligand and Channel Research

28 April 2010

Number of times this article has been viewed

\author{
Tilman E Klassert ${ }^{1,2}$ \\ Shyam A Patel ${ }^{1,3}$ \\ Pranela Rameshwar' \\ 'Department of Medicine - Division \\ of Hematology/Oncology, \\ New Jersey Medical School, ${ }^{3}$ Graduate \\ School of Biomedical Sciences, \\ University of Medicine and \\ Dentistry of New Jersey, Newark, \\ NJ, USA; ${ }^{2}$ Instituto de Enfermedades \\ Tropicales y Salud Pública, University \\ of La Laguna, Canary Islands, Spain
}

Correspondence: Pranela Rameshwar UMDNJ-New Jersey Medical School, MSB, Rm. E-579, 185 South Orange Ave, Newark, NJ 07103, USA

$\mathrm{Tel}+\mathrm{I} 9739720625$

Fax +I 9739728854

Email rameshwa@umdnj.edu

\begin{abstract}
After many decades of neuropeptide research, advances in the field of tachykinins have considerably increased and revealed their implications in several physiological processes. In this review we focus on the role of the tachykinins in the regulation of hematopoietic functions. Evidence has shown that neural control of this process is emerging as a significant category in hematopoietic modulation. In the context of this regulation, we discuss the existence of a complex network involving the neurokinin receptors, tachykinins and cytokines. This network is tightly regulated by each of its components.
\end{abstract}

Keywords: hematopoiesis, tachykinins, neurokinin receptor, crosstalk, regulation

\section{Introduction}

The adult immune system arises from a definitive number of hematopoietic stem cells in the bone marrow (BM). This process, termed hematopoiesis, is orchestrated through a complex series of events, in which soluble factors play a critical role. ${ }^{1}$ These soluble factors include cytokines, chemokines, neurohormones and neuropeptides. ${ }^{2-6}$ These mediators have been shown to be involved in the interactions between the brain, BM, and immune system, and known as the neural-hematopoietic-immune axis. ${ }^{5}$ Neural control of hematopoiesis is emerging as a central category in hematopoietic regulation. Bidirectional crosstalk between the neurological mediators and hematopoiesis has been demonstrated by various studies and has been shown to serve as a regulatory mechanism. ${ }^{5,6}$ This crosstalk mainly occurs by the release of neuropeptides termed tachykinins from innervated fibers. These neuropeptides interact with specific receptors on BM resident cells and release other hematopoietic regulators such as cytokines, forming a complex network that regulates hematopoiesis. ${ }^{5,6}$ This review focuses on the role of tachykinins and their receptors in hematopoiesis and discusses how their crosstalk and regulation allows for maintenance of homeostasis in the BM.

\section{Tachykinins}

Tachykinins comprise of a family of structurally related and evolutionary conserved peptides characterized by the common carboxy-terminal sequence FXGLM- $\mathrm{NH}_{2} \cdot{ }^{7}$ Substance P (SP), Neurokinin A (NKA) and Neurokinin B (NKB) are the best known members of this family. Von Euler and Gaddum identified the first tachykinin, SP, in 1931. ${ }^{8}$ Forty years later, it was chemically characterized by Chang and Leeman. ${ }^{9}$ In the mid-1980s, NKA and NKB were identified by multiple groups, ${ }^{10-12}$ and since then, tachykinins have been extensively studied for their roles in many pathological and physiological processes, including hematopoiesis. ${ }^{13}$ 
The three known genes that encode mammalian tachykinins are $T A C 1, T A C 3$, and $T A C 4$, also termed as preprotachykinin A (PPT-A), -B (PPT-B), and -C (PPT-C), respectively. ${ }^{7} T A C 1$ encodes SP, NKA, and the extended forms of NKA (NPK and NP $\gamma$ ). TAC3 encodes for NKB, and the recently discovered $T A C 4$ gene encodes for the new tachykinin members, hemokinin-1 (HK-1), its N-terminally extended forms endokinin A (EKA), endokinin B (EKB), and the tachykinin-related peptides endokinin $\mathrm{C}$ (EKC), and endokinin D (EKD). ${ }^{7}{ }^{14}$ Biosynthesis of the tachykinins includes posttranscriptional processing of these genes, leading to their different splice variants. ${ }^{15}$ Translation of these mRNAs and posttranslational processing ends with a peptide $\alpha$-amidation and gives rise to the different tachykinins. ${ }^{16,17}$ The ultimate sequence is a deca- or undecapeptide for most of the tachykinins. ${ }^{15-17}$ Other smaller forms of each member of the tachykinin family can be generated by enzymatic degradation of endogenous enzymes. As an example, a 4-amino acid peptide (SP [1-4]) can be generated by digestion of SP with human BM-derived endopeptidase. ${ }^{18}$ This small peptide showed negative effects on hematopoietic regulation, which contrasted the stimulatory effect SP. ${ }^{5,18}$ This underscores the complex functions of tachykinins, which could occur in multiple tissues and organs.

Tachykinins are widely distributed within both the central and the peripheral nervous system. ${ }^{7}$ Despite the initial consideration of tachykinins as neuropeptides, tachykinins have been shown to be not merely restricted to nerves, as their expression has been identified in non-neural tissues including cells of the BM and mature blood cells. ${ }^{7,19,20}$ In fact, the recently discovered third tachykinin gene TAC4 is predominantly expressed in nonneural tissues. ${ }^{20}$ The tachykinins can be considered as soluble links between the nervous system and other organs. As an example, the tachykinins have been shown to mediate a link within the neural-immune-hematopoietic axis. ${ }^{5,21}$

The wide distribution of the tachykinins has implicated this family of peptides with several other physiological and pathological processes. However, this review will focus on the tachykinins as hematopoietic modulators. Functional homeostasis by members of the tachykinins include processes of reproduction, blood pressure and nociception..$^{15,22}$ The major tachykinin, SP, has been associated to varied pathological processes, such as its facilitating role in HIV-1 infection and hematological and nonhematological malignancies. ${ }^{15,23,24}$ Due to the presence of the tachykinins in the neural system, it is not a surprise that this family of peptides would be linked to neurological conditions, such as depression, anxiety,
Parkinson's disease and Alzheimer's diseases. ${ }^{25-27}$ The tachykinins have also been implicated in traumatic brain injury, ischemic encephalopathy and epileptic seizures. ${ }^{28-30}$ Most of the biological actions of tachykinins are exerted by their binding to the NK receptors. ${ }^{15}$

\section{Neurokinin receptors}

Neurokinin receptors belong to family 1 (rhodopsin-like) of G protein-coupled receptors (GPCRs), which play a key role in cell signaling. ${ }^{31,32}$ GPCRs are characterized by sharing the same structural motif, including seven hydrophobic transmembrane domains with three extracellular loops and three intracellular loops. ${ }^{32-34}$ GPCRs are able to recognize a variety of ligands and stimuli from the extracellular environment and transmit information to the interior of the cell by interacting with the G-proteins. By activation of second messengers, GPCRs regulate a highly interconnected network of chemical pathways. ${ }^{35}$ The importance of these receptors becomes apparent since half of the commercially available drugs target the superfamily of GPCRs. ${ }^{15}$

Currently, three different NK receptors have been identified, named NK1, NK2 and NK3. Although naturally occurring tachykinins can act as full agonists on any of the NK receptors, SP and HK-1 exhibit preferential binding to the NK1 receptor, whereas NKA and NKB show more affinity to NK2 and NK3 receptors, respectively. ${ }^{15,34}$ Three different genes termed TAC1R,TAC2R, and $T A C 3 R$ encode for the NK1, NK2, and NK3 receptors, respectively. ${ }^{31,34}$ These evolutionary conserved genes contain five exons interrupted by introns. Interestingly, the feature to retain introns is rather uncommon in the superfamily of GPCRs. Nevertheless, this characteristic of the neurokinin receptors permits the generation of functionally different splice variants, which have been observed for both NK1 and NK2 receptors. ${ }^{15}$ For example, two different TACR 1 isoforms have been described differing in the length of their C-terminal tails, and thus in their functional properties. ${ }^{36,37}$ Recent studies have related the expression of these isoforms to innate immunity and HIV neuropathogenesis. ${ }^{38,39}$

The tachykinin NK1 receptor is ubiquitously expressed in mammals and has been found in neurons, vascular endothelium, muscle, different immune cells, and BM, among others. ${ }^{7,19,35}$ The tachykinin NK2 receptor is mostly expressed in peripheral tissues with restricted expression in the central nervous system (CNS). ${ }^{34}$ Finally, the tachykinin NK3 receptor is preferentially expressed in the CNS. ${ }^{34}$ Regarding hematopoietic cells, NK1 and NK2 expression 
has been established in mature immune cells, hematopoietic progenitors, mesenchymal stem cells (MSCs) and BM stroma. $^{13,19}$

Reports of tachykinin-mediated processes which seem to be NK receptor-independent, ${ }^{40}$ and the recent identification of novel tachykinins ${ }^{22}$ have reopened the question about the existence of a fourth NK receptor. While attempts to find additional NK receptors have been unsuccessful, the question remains a focal point due to the identification of tachykinins that appear to interact with receptors other than those of the NK family; and crosstalk between NK receptor subtypes in human models of hematopoiesis. ${ }^{41}$

The intracellular signaling pathways following NK1 and NK2 activation are complex, similar to all GPCRs. Among the possible intracellular signaling pathways activated by GPCRs, NK1 and NK2 activation has been shown to evoke both calcium $\left(\mathrm{Ca}^{2+}\right)$ and cyclic adenosine monophosphate (cAMP) responses. ${ }^{42-44}$ The primary G-protein responsible for $\mathrm{Ca}^{2+}$ triggering pathways is $\mathrm{G \alpha q}$, whereas Gos activates adenylase cyclases. ${ }^{44} \mathrm{NK}$ receptors can also bind Goi, which inhibits the adenylase cyclases. ${ }^{35}$ Downstream mediators of the different $\mathrm{NK}$-induced pathways include protein kinases A (PKA) and C (PKC), Ras, Raf-1, MAP/ERK kinase (MEK), extracellular signal-regulated kinase (ERK) and NFkB. ${ }^{4-46}$ Recently, a new NK1 receptor signaling cascade via phosphoinositide-3 kinase (PI3K)-Akt has been demonstrated in studies with mouse dendritic cells. ${ }^{47}$ Similar activation has been reported for human non-tumorigenic breast cells. ${ }^{48}$ Nevertheless, classic NK1 receptor signaling mostly involves phospholipase C (PLC) as a second messenger producing inositol triphosphate (IP3) and diacylglycerol (DAG), with the downstream release of $\mathrm{Ca}^{2+}$ and PKC activation. These findings suggest that Goq is the dominant G-protein subunit in NK1 activation. ${ }^{46}$ $\mathrm{Ca}^{2+}$ response also seems to be the preferential pathway in NKA/NK2-receptor activation. ${ }^{44}$ However, it should be noted that these studies were performed in cell lines, which are by definition, cells with a degree of transformation. These findings will need to be taken speculatively in studying primary cells, which might show tissue specificity. The intracellular signal transduction pathways of NK receptor signaling could be subjected to termination by a variety of GPCR kinases (GRKs) and second messenger-regulated kinases. ${ }^{49}$ This could occur by the phosphorylation of the NK receptors and recruitment of the cytosolic scaffolding proteins arrestins to prevent additional interactions. ${ }^{50}$ The recruitment of the arrestins could be linked to receptor recycling, although the method of recycling might be cell-specific. ${ }^{51,52}$
The ability of NK receptors to activate different effector systems has been explained, at least in part, by the finding that GPCRs exist in equilibrium between different active conformations. ${ }^{15,53}$ In this multistate model of GPCR activation, both the extracellular microenvironment and also the ligand seem to condition the conformation adopted by the receptor and thus the activation of one or more pathways. ${ }^{15}$ This has been demonstrated for the NK1 receptor, after observing its different binding affinities to either SP or the nonnatural ligands NKA and Septide. ${ }^{54}$ Similar evidence has been shown for the NK2 receptor, where the truncated form of NKA (NKA-(4-10)) evokes only a $\mathrm{Ca}^{2+}$ response whereas the binding of naturally occurring, full-length, NKA caused the accumulation of cAMP. ${ }^{44}$ Despite the experimental studies with ligands, the limiting factor for functions could be the receptor. This is demonstrated by in vitro studies on hematopoiesis with human bone marrow cells. Stimulation with the tachykinins and in the presence, or absence of, receptor antagonists indicated that the receptor, and not the ligand limits the function of the particular ligand. ${ }^{5,6,55,56}$ If SP interacts with NK1 by in vitro studies, the outcome recapitulates hematopoietic stimulation. ${ }^{55}$ Similar stimulation with NKA through NK2 resulted in the opposite outcome. ${ }^{56}$

\section{Hematopoiesis}

Hematopoiesis is the process by which blood and immune cells are generated from hematopoietic stem cells (HSCs) by differentiation along multiple lineages. ${ }^{57,58} \mathrm{HSCs}$ can self-renew and can show long-term repopulation of an animal's immune system. The HSCs are located in low $\mathrm{O}_{2}$ regions of the $\mathrm{BM}$, close to the endosteum. ${ }^{59}$ Long-term reconstituting HSCs can give rise to short-term repopulating cells, which then yield common lymphoid progenitors (CLPs) and common myeloid progenitors (CMPs), with each being able to differentiate along multiple lineages to produce both immune and blood cells. ${ }^{60}$ CLP gives rise to B cells, T cells, and natural killer cells whereas CMP produces erythrocytes, megakaryocytes, monocytes, basophils, neutrophils and eosinophils. ${ }^{13,58}$ The process of hematopoiesis is tightly regulated at several levels by a complex network of soluble factors, including cytokines and neuropeptides. ${ }^{13}$

The regulation of hematopoiesis involves functional support of HSCs by the BM niche. ${ }^{1,61}$ This niche could stimulate hematopoiesis as well as exert negative feedback to maintain homeostasis in BM. As an example, MSCs, can negatively regulate hematopoiesis via the generation of adipocytes. ${ }^{61,62}$ This role of MSCs is important when one considers that MSCs are located around the main blood 
vessels of the marrow cavity where they are bypassed by cells entering and exiting the marrow. ${ }^{5,63}$ Another important role for MSCs is their ability to differentiate into two of the hematopoietic-supporting cells, stroma and osteoblasts. ${ }^{64}$ These hematopoietic-supporting cells are located near the endosteal area of the bone in a relatively hypoxic microenvironment. ${ }^{1,65}$ Although in vitro studies have demonstrated a significant role of NK receptors and the tachykinins in the functions of stroma in hematopoietic regulation, further studies are required with in vivo models. These studies are particularly important because stromal cell interactions with HSCs are relevant to the functions of HSCs, such as migration and progenitor expansion versus hematopoietic reconstitution. ${ }^{66,67}$ It appears that there is heterogeneity among stromal cells in the $\mathrm{BM}$ and this is relevant to stromal interaction with the HSCs. ${ }^{68}$ This finding is significant because it lends itself to future studies geared towards determining if subsets of stroma show varied expressions of NK receptors.

Hematopoiesis is regulated by soluble regulators such as cytokines, chemokines, and growth factors. ${ }^{1}$ Cytokines are the prototypical regulators of hematopoiesis. ${ }^{2}$ The hormone erythropoietin is also important to hematopoietic regulation, in particular in the erythroid phase. ${ }^{2}$ Significant cytokines that are linked to the tachykinins include stimulatory interleukins (ILs) such as IL-1, IL-3, IL-6, IL-11 or the pro-inflammatory cytokine tumor necrosis factor- $\alpha$ (TNF- $\alpha$ ), and inhibitory factors such as macrophage inflammatory protein- $1 \alpha$ (MIP-1 $\alpha$ ) and transforming growth factor- $\beta$ (TGF- $\beta$ ), among others. ${ }^{2,5,69}$ Similarly, SP is linked to the receptor/ligand interaction between stem cell factor (SCF) and c-kit, which has trophic effects on hematopoiesis. ${ }^{70}$ Cytokines are not only relevant to specific sites of hematopoiesis, but they are important across the cavity, where various maturational stages of hematopoietic progenitors can be located. Gradient changes of growth factors are significant to the outcome of hematopoiesis. ${ }^{71,72}$ Among the functions of cytokines is the role of matrix metalloprotease activity that regulates the decision of HSCs to retain cell cycle quiescence or to exit the cycling state. ${ }^{73}$ The discussion in this section is not only relevant to hematopoietic homeostasis, but to hematopoietic failure pathologies, such as leukemias and myeloproliferative disorders. Appreciation of the relevance of cytokines and other factors requires studies on the tachykinins and neurokinins to enhance and understand BM functions.

The literature on BM innervation by the sympathetic and peptidergic fibers have led to deeper insights into the neural role of hematopoietic regulation. ${ }^{74,75}$ Since evidence has shown that neuropeptides, neurotransmitters, neurotrophic factors and neurohormones are involved in hematopoiesis, neural control of this process is emerging as another category in hematopoietic regulation..$^{3-5,75-78}$ Moreover, it has been shown that peptides of neural origin establish a network with classical regulators of hematopoiesis. ${ }^{6}$ This network connects the BM, brain, and the immunological system, and these regulators demonstrate intercellular crosstalk.

\section{Tachykinins in the neural- hematopoietic-immune axis}

The links among the brain, $\mathrm{BM}$ and immune system were established by anatomical studies. ${ }^{5,79,80}$ An understanding of these interorgan links is important to appreciate how the tachykinins could be involved in the loss of homeostasis, which could be due to BM-derived dysfunction or the movement of malignant cells in the BM. This section will link the varied dissected information on the tachykinins to hematopoiesis and immune functions ${ }^{81}$ (Figure 1). The BM receives innervations by substance $\mathrm{P}$-secreting neurons, as well as other neurotransmitters. ${ }^{82}$ The nervous system may serve as the source of upsurge in hematopoiesis, which is then fine-tuned by cytokine signaling. ${ }^{5}$

A well-studied receptor/ligand interaction that is involved in the functions of HSCs is the chemokine stromal cellderived factor 1 (SDF-1 or CXCL12), and its receptor, CXCR $4 .{ }^{1}$ CXCL12 also regulates inflammation, and disruption studies of CXCL12-CXCR4 by the antagonist AMD3100 have demonstrated that this ligand-receptor pair is important in the mobilization of HSCs from BM to the periphery. ${ }^{72,80,83,84} \mathrm{SDF}-1$ also contributes to cell migration, cell survival and angiogenesis. ${ }^{85}$ An increase in CXCL12 could lead to hematological malignancies, as well as the metastasis of cancer cells to BM..$^{72,85}$ If CXCL12 is relevant to BM functions, the question is how its biology can be facilitated by the tachykinins.

In vitro studies with cells from human BM aspirates strongly suggest that the neural-hematopoietic-immune axis could involve a crosstalk between CXCL12 and TAC1 peptides ${ }^{80}$ Functions of CXCL12 on BM homeostasis are not limited to hematopoietic regulation, they are also involved in the pathology of BM. The role of CXCL12 appears to be secondary to the induction of $T A C 1$, and this could lead to the entry of human breast cancer cells into BM..$^{81,86}$ Both breast cancer cells and hematopoietic cells demonstrate constitutive expression of $T A C 1 .{ }^{81}$ The roles for $T A C 1$ in angiogenesis, metastasis and survival of cancer cells are significant for entry of human cancer cells to BM ${ }^{81}$ While CXCL12 is discussed 


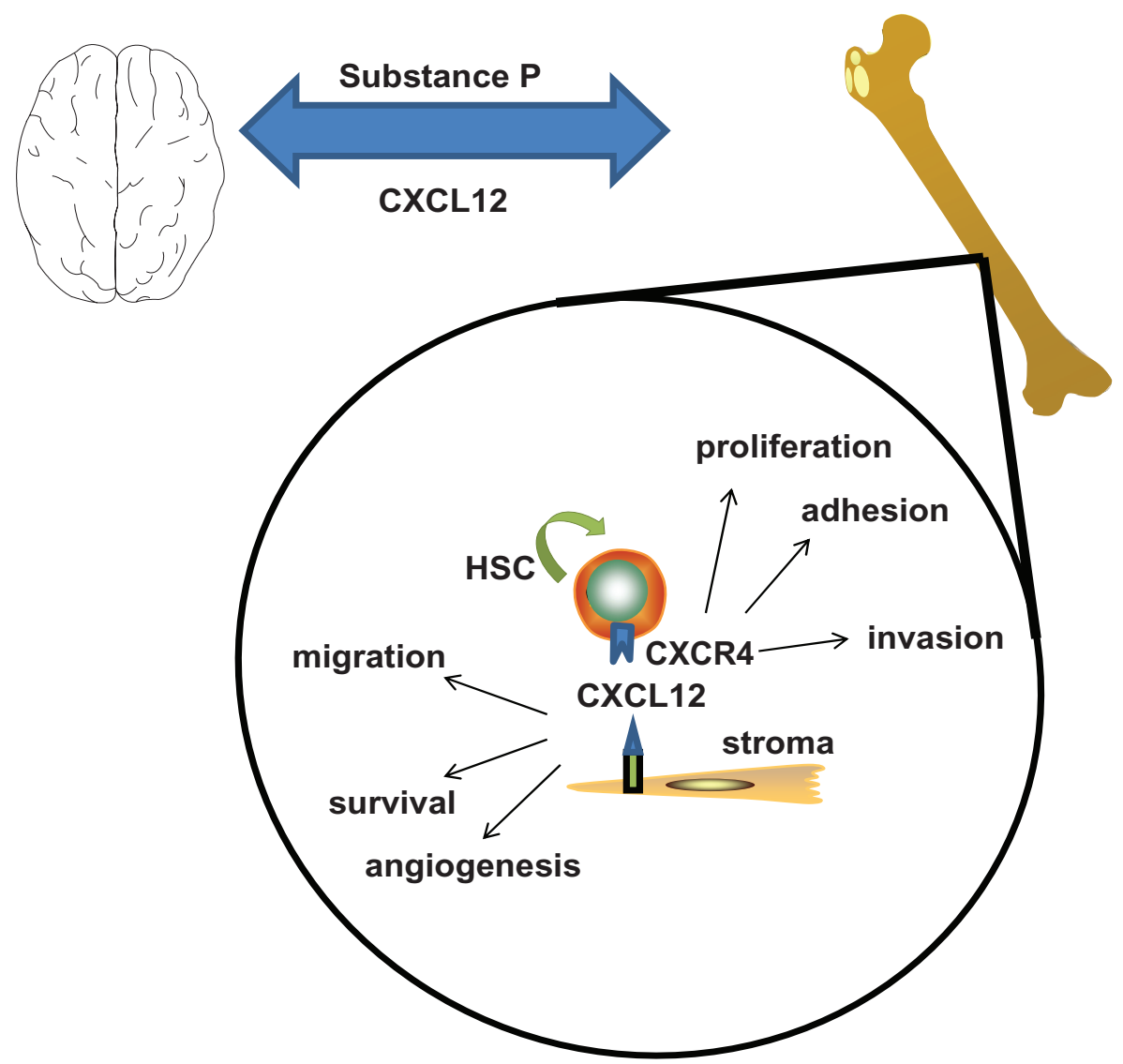

Figure I Neural control of hematopoiesis involves bidirectional interactions between the brain and bone marrow.

Notes: This connection with the immune system is referred to as neural-immune-hematopoietic axis. Hematopoietic stem cells (HSCs) interact with cells of the bone marrow (BM) microenvironment (eg, stroma) through CXCR4 and membrane-bound SDF-I on cells of the microenvironment. Disruption of this interaction can cause the migration of self-renewing HSCs from the BM. Increased production of SDF-I could be linked to hematological disorders due to its role in angiogenesis and cell survival.

in this section, expression of other cytokines may also be secondary to the expression of $T A C 1$ and $N K$ receptors. ${ }^{81}$ The oncogenic properties of TAC1 involve the loss of the tumor suppressor gene $R E S T{ }^{86}$

In addition to CXCL12, SP can mediate an increase in the production of granulocyte-macrophage colony stimulating factor (GM-CSF) in human BM mononuclear cells. ${ }^{73,87}$ This growth factor could be important in the mobilization of HSCs, and might act in concert with CXCL12 ${ }^{87}$ In summary, this section describes a role for TAC1 in $\mathrm{BM}$ functions during homeostasis, mobilization of HSCs and metastasis of breast cancer into $\mathrm{BM}$; underscoring the emerging role of the tachykinins in BM functions.

\section{Tachykinins and neurokinin receptors in hematopoiesis}

Experimental studies with human BM aspirates from healthy subjects and patients with myeloproliferative disorders, with or without fibrosis, showed relevance for NK1 and NK2 in BM homeostasis and during dysfunctions. . $^{5,13,18,88}$ The most reported tachykinins involved in hematopoiesis are SP and NKA. ${ }^{5,13}$ These TAC1 peptides can be present in $\mathrm{BM}$ through two sources: release by the innervating nerve fibers; and the production in resident human BM cells such as endogenous stromal cells. ${ }^{89-91}$ The role of SP and NKA in hematopoiesis is mostly based on in vitro studies with human BM aspirates of healthy subjects. ${ }^{13,18}$ The findings, however, have been extrapolated to studies with patients' aspirates and peripheral blood, which indicated that substance $\mathrm{P}$ is important in the pathology of the BM. $.^{5,13,88} \mathrm{HK}-1$, a tachykinin from $T A C 4$, has also been implicated in B- and T-cell human lymphopoiesis, again, by in vitro methods. ${ }^{13,92}$

SP and NKA have been shown to regulate hematopoiesis at various stages of the hematopoietic hierarchy. ${ }^{13}$ These studies have been demonstrated with human and murine BM cells. ${ }^{5,75,93}$ Studies with a murine model on the lymphoid 
lineage have demonstrated a role for SP in B-cell maturation. ${ }^{93}$ In the erythro-myeloid lineage, SP mediates stimulatory effects on their progenitors. ${ }^{5,13}$ Contrary to SP, NKA exerts diverse effects on erythroid progenitors and inhibits proliferation of granulocytic-monocytic progenitors. ${ }^{13,56}$ Together, these findings indicate that the TAC1 gene can regulate hematopoiesis not only through stimulatory effects, but also through its own negative feedback. ${ }^{6,41,56,94}$ This conclusion is supported by studies with human cells that correlate with the production of relevant cytokines. ${ }^{5,6}$ However, the significance of these studies require more in-depth analysis with molecular approaches as well as in vivo models with knockout and transgenic mice.

To date, the experimental studies on the role of the hematopoietic microenvironment indicate that BM stroma could be a critical cellular link in the crosstalk between the tachykinins and hematopoiesis ${ }^{5,56}$ (Figure 2A). In vitro studies with stroma from human BM aspirates have shown that each tachykinin induces the production of specific cytokines. $5,55,56$ SP interacts with NK1 on the human stromal cells or human BM mononuclear cells to induce the production of stimulatory mediators such as IL-1, IL-2, IL-3, IL-6, TNF- $\alpha$, SCF and GM-CSF. ${ }^{5,87,95-102}$ The proliferative effects observed by SP-NK1 coupling on hematopoietic cells are therefore partly explained by indirect production of cytokines and growth factors involved, among other processes, in cell-cycle transition. ${ }^{82}$ On the other hand, NKA may be relevant to cell cycle control via checkpoint regulation, potentially conferring protective effects on HSCs. ${ }^{103}$ NKA induces the release, by stromal cells, of the inhibitory cytokines MIP- $1 \alpha$ and TGF- $\beta .{ }^{56}$ Recently, a direct NK2-mediated regulation mechanism has also been described, by which NKA inhibits cell-cycle transition in the human hematopoietic progenitor cell line K562. ${ }^{104}$ Although NK2 is expected to activate G-protein-linked pathways, the effect of NKA on K562 occurs through Smad proteins. This finding is highly suggestive that there could be intracellular crosstalk between NK2 and other activators. The interaction between NKA and NK2 leads to the activation of the cell cycle inhibitors, p53, p21 and Smad4, while suppressing the cell cycle activators $\mathrm{Cdk} 2$ and CyclinA. ${ }^{104}$

\section{Neurokinin receptor crosstalk in hematopoietic functions}

The effects of NK1 and NK2 on hematopoiesis are divergent. ${ }^{6,41,94}$ NK1 mediates the production of cytokines linked to hematopoietic stimulation, whereas NK2 activation induces inhibitory mediators. ${ }^{5,56}$ Therefore, it seems logical that the expression of either NK1 or NK2 could determine the outcome of hematopoietic functions. Indeed, co-expression of both receptors is not observed in most human BM resident cells, in particular the stromal cells. ${ }^{6,41}$ Moreover, the induction of one NK subtype correlates with a decrease of the other subtype, showing a "yin-yang" type of expression, at least in human stromal cells. ${ }^{82}$ This is relevant to hematopoietic functions since the stromal cells are critical in the support of hematopoiesis.

Neurokinin receptors have been shown to be able to regulate their own expression (Figure 2B). SP-NK1 interaction can induce $T A C 1 R$ transcription, a process mediated by the activation and translocation to the nucleus of NFKB. ${ }^{82,105}$ Cytokines induced by NK1 activation, such as IL-1, IL-3, IL-6 and GM-CSF, can constitute an indirect stimulation method of NK1 receptor production. ${ }^{41,105}$ The regulatory region of NK1 indicated that binding sites for $\mathrm{NF} K \mathrm{~B}$ and cAMP response element (CRE) are important in controlling the responses to cytokines in the induction of NK1. ${ }^{105,106}$ Recently, auto-regulation of the NK2 receptor was also noted. In both primary BM cells and progenitor cells, NK2 receptor activation by NKA leads to increased expression of its own mRNA. ${ }^{103}$ In this case, TAC2R transcription seems to be mediated by $\mathrm{p} 53$ activation and its binding to the gene promoter. ${ }^{103}$ The induction of the NK2 receptor by NKA is also regulated by autocrine production of TGF- $\beta$ in stroma. ${ }^{41}$

The complex biology of the NK receptors is compounded by evidence of intracellular crosstalk between the subtypes within primary human BM stroma. ${ }^{41}$ Use of a specific NK2 receptor antagonist in an in vitro model of human hematopoiesis, resulted in enhanced hematopoietic response by $\mathrm{SP}^{41}$ These studies indicated that in the absence of NK2, the balance in hematopoietic function by NK1 is altered. The enhancement of hematopoietic activity correlated with NK1 receptor upregulation at both protein and mRNA levels. ${ }^{41}$ On the other hand, blunting of the NK1 receptor resulted in the reduction of cell proliferation, and upregulation of the NK2 receptor at both protein and mRNA levels. ${ }^{41}$ These results indicated the existence of intracellular crosstalk between NK1 and NK2 and this crosstalk is highly relevant to hematopoietic balance. The molecular mechanisms underlying intracellular crosstalk between NK1 and NK2 are under investigation and might hold the key to several disorders linked to diseases.

GPCR signaling generally involves the activation of different secondary messengers, such as PKC and PKA that can mediate receptor crosstalk. ${ }^{107}$ This could occur by converging and/or counteracting signaling pathways 


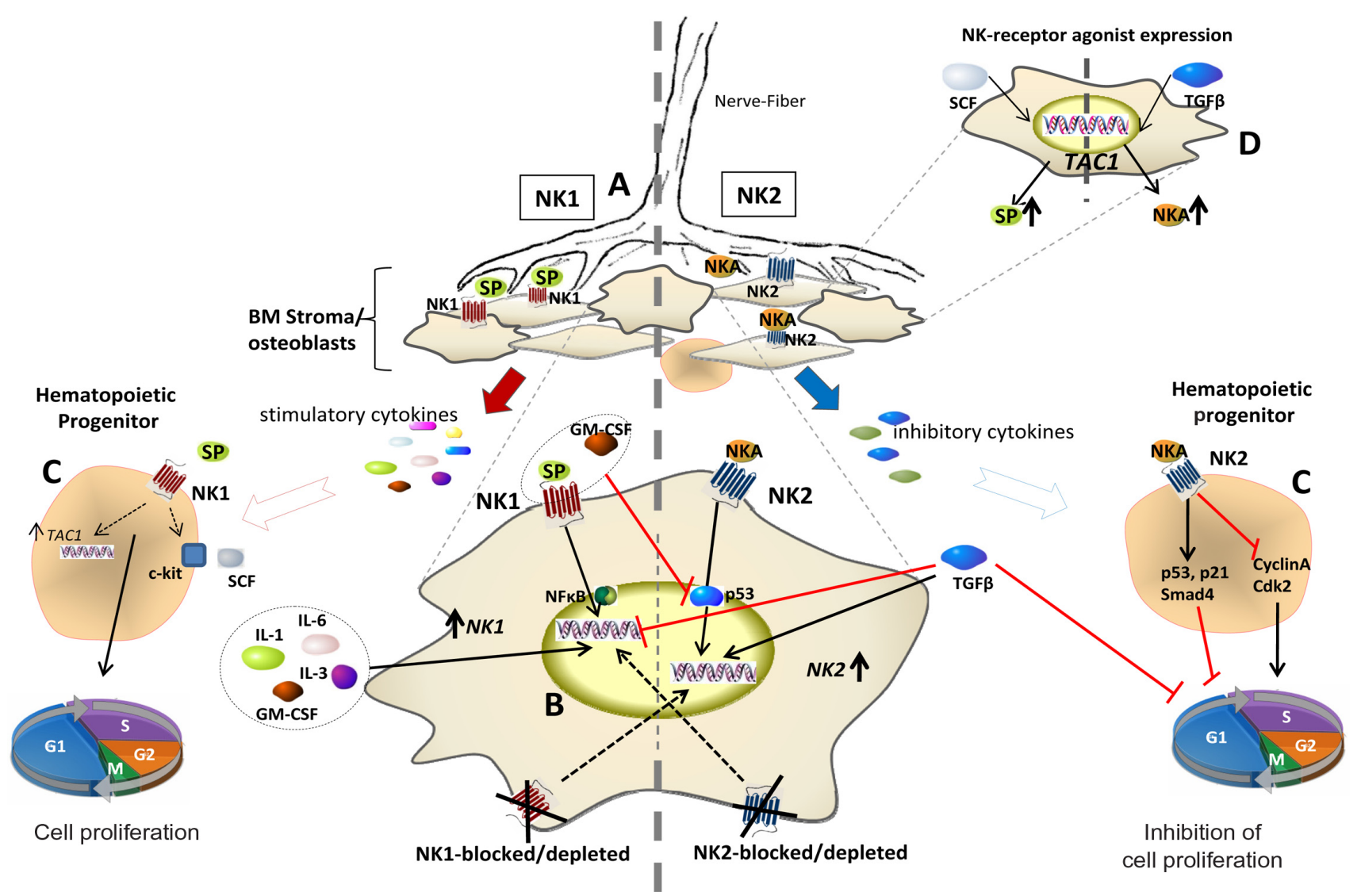

Figure 2 Illustration summarizes the involvement of NK receptors on hematopoietic regulation and the outcome of crosstalk between NKI and NK2.

Notes: Left: shows the NKI-mediated stimulation; Right: NK2-mediated hematopoietic inhibition. Substance P(SP) interaction with NKI leads to stroma-mediated production of stimulatory cytokines, and neurokinin-A (NKA) stimulation resulted in the release of inhibitory cytokines (A). Crosstalk between these receptors is partly explained by the expressions of NKI and/or NK2, respectively. Expression of each gene is tightly regulated by SP, NKA and their induced cytokines (B). NKI or NK2 expression causes hematopoietic stimulation or inhibition, respectively (C). The production of a particular TACI peptide depends on the ligand, SCF by SP and TGF- $\beta$ by NKA (D). Black arrows depict upregulation; Red lines depict downregulation.

following receptor activation. ${ }^{108,109}$ As discussed above, several intracellular pathways can be activated by GPCRs. The activation of NK1 and NK2 mostly involve pathways that include $\mathrm{Ca}^{2+}$ and PKC. ${ }^{42,44}$ The activation of PKC leads to the downstream activation of ERK1/2 and NF $\kappa B$. ${ }^{109}$ In other studies, NK1 stimulation led to the activation of the PI3K-Akt pathway in dendritic cells. ${ }^{47}$ This brings up a question of cellspecific signaling pathways in the activation of NK1 versus newly identified mechanisms from NK receptor activation. Similar pathways in activated macrophages suggest that the PI3K-Akt signaling pathway might be relevant to antigen presenting cells. ${ }^{109}$ Furthermore, the importance the PI3KAkt signaling pathway has been shown in NK1-mediated inflammatory responses, in macrophages, interacting with the PKC-ERK1/2-NFKB signaling pathway. ${ }^{109}$

Beside NFKB, transcription factors binding CRE have also been shown to be implicated in NK1 regulation. These are downstream of the cAMP pathway, which is also linked to NK1 and NK2 activation. ${ }^{42,44,105}$ It has been suggested that this pathway could also inhibit NK1 expression through the inducible cAMP early repressor (ICER). ${ }^{105,110}$ While it is important to map intracellular pathways that are activated by the NK receptors and to understand how these receptors are regulated, further insights will be gained by studies to decipher how these pathways interact with each other to regulate the biology of the NK subtypes within a milieu of factors such as inflammatory mediators.

Crosstalk between NK receptor subtypes can be partly explained by indirect cytokine-mediated regulation. ${ }^{5,82} \mathrm{We}$ have already exposed how each receptor is able to induce its own expression by specific cytokines and transcription factors. Similarly, a particular NK receptor subtype can induce a specific cytokine to inhibit the expression of the other receptor subtype. ${ }^{41,103}$ These regulatory networks are important to functions. As an example, it has been demonstrated that SP and GM-CSF were able to negatively control the NKA-NK2-p53 induced stimulation of NK2 expression, with concomitant downregulation of p53 in a 
human hematopoietic progenitor cell line. ${ }^{103}$ On the other hand, TGF- $\beta$, an NK2-induced cytokine, can decrease the expression of NK1 in primary human BM stroma. ${ }^{41}$ Figure 2 shows the intricate interplay between tachykinins, cytokines and growth factors that leads to the expression of either NK1 or NK2 receptors, and thus, to either a stimulatory or a inhibitory effect on hematopoiesis. This interplay begins or terminates, depending on the context of the biological process, at the level of gene expression.

The regulation and crosstalk among the NK receptors is not limited to intracellular interactions, it also involves physical interactions at the cell membrane. ${ }^{111} \mathrm{~A}$ discussion of how this occurs by other GPCRs could be extrapolated to NK receptor subtypes. For example, heterodimerization of the prostaglandin $\mathrm{E}_{2}$ type-1 receptor (EP1R) and the $\beta_{2}$-adrenergic receptor $\left(\beta_{2} A R\right)$ in airway smooth muscle cells can lead to uncoupling between $\beta_{2} \mathrm{AR}$ and its G-protein to reduce the outcome of the natural ligand. ${ }^{111}$ Further studies may explain whether GPCR dimerization plays a role in NK1 and NK2 intracellular crosstalk.

TAC1 peptides, SP and NKA, are the natural ligands which activate both the NK1 and the NK2 receptor. ${ }^{15}$ Thus, besides the regulation of the TAC1R and TAC2R genes, TAC1 expression will also be a deciding factor in keeping the balance between NK1 and NK2 receptor mediated actions. At this level, CXCL12 has been shown to regulate TAC1 expression and this effect is concentration-dependent, indicating that this chemokine exerts a fine control of TAC1 expression. ${ }^{63}$ The RE-1 silencer of transcription (REST) synergizes with NFאB in TAC1 repression in BM-derived MSCs. ${ }^{12}$ Moreover, $T A C 1$ is known to give rise to different splice variants, a process which becomes a key factor for differential SP/ NKA expression. ${ }^{24,34}$ It is unclear why a transcript that can produce both SP and NKA results in varying ratios of these two peptides. These are gaps in the biology of TAC1 that need to be studied, since the level of SP and NKA are highly significant to the functional outcome of this gene.

The sequence coding for SP is localized on exon 3, which is present in all four TAC1 transcripts ( $\alpha, \beta, \gamma$, and $\delta$ ). Exon 6, which contains the sequence coding NKA, is present only in $\beta$ - and $\gamma$-transcripts. ${ }^{34} \mathrm{~A}$ possible model of TAC1 regulation by miRNAs and RNA-binding proteins (RBPs) has been recently proposed in stromal cells. ${ }^{79}$ Hematopoietic stimulatory cytokines, such as SCF and IL-11, and the inhibitory cytokine TGF- $\beta$ were able to induce interaction between RBPs and TAC1 mRNA. In both cases, specific TAC1 miRNAs were degraded and downregulated; and the binding avidity of these RBPs to the RNA was observed to be different in each case. Interestingly, the ratios of SP:NKA were different, with stimulatory cytokines leading to increased SP production and TGF- $\beta$, giving rise to higher levels of NKA (Figure 2D). ${ }^{79}$ Since these studies were performed with BM stromal cells it is unclear if these findings can be extrapolated to other cell types without investigative studies.

The microenvironment in which the ligand-receptor interactions take place constitutes another level of signaling regulation. It houses a variety of extracellular matrix proteins, such as fibronectin, which are critical to HSC function and protection. ${ }^{5,88}$ Fibronectin can induce mobilization of SP to allow it to come into contact with HSCs. This phenomenon is relevant to $\mathrm{BM}$ homeostasis and hematopoiesis. Fibronectin also protects SP from degradation by endogenous endopeptidases. ${ }^{113}$ This has great importance since SP fragments derived from endopeptidase activity, such as SP(1-4), could exert hematopoietic regulation. ${ }^{18}$ Indeed, SP $(1-4)$ has been shown to have inhibitory effects, and thus an opposite action to SP, on hematopoiesis. ${ }^{18}$

Taken together, this review discusses the existence of a complex network involving the neurokinin receptors, their ligands and cytokines. These parameters in this network are subjected to tight regulation, partly by receptor crosstalk at several levels. These NK receptor interactions may comprise: cytokine-mediated pathways; intracellular signaling; and molecular crosstalk. Regulation of this network has not only diverse physiological implications in the BM, but also pathological implications. Disruption of BM homeostasis has been linked to hematological disorders, such as BM fibrosis and leukemia. ${ }^{5,24}$ The current state of evidence warrants further research in this field.

\section{Acknowledgment}

This work was supported by the FM Kirby Foundation and the FPU grant AP2005-4921 to Tilman E. Klassert.

\section{Disclosures}

The authors report no conflicts of interest relevant to this research.

\section{References}

1. Patel N, Castillo M, Rameshwar P. An in vitro method to study the effects of hematopoietic regulators during immune and blood cell development. Biol Proced Online. 2007;(9):56-64.

2. Metcalf D. Hematopoietic cytokines. Blood. 2008;111(2):485-491.

3. Van Hagen PM, Krenning EP, Kwekkeboom DJ, et al. Somatostatin and the immune and haematopoetic system: a review. Eur J Clin Invest. 1994;24(2):91-99.

4. Maestroni GJM. Adrenergic regulation of haematopoiesis. Pharmacol Res. 1995;32(5):249-252. 
5. Greco SJ, Corcoran KE, Cho CJ, Rameshwar P. Tachykinins in the emerging immune system: relevance to bone marrow homeostasis and maintenance of hematopoietic stem cells. Front Biosci. 2004;(9):1782-1793.

6. Rameshwar P, Poddar A, Gascón P. Hematopoietic regulation mediated by interactions among the neurokinins and cytokines. Leuk Lymphoma. 1997;28(1-2):1-10.

7. Pinto FM, Almeida TA, Hernández M, Devillier P, Advenier C, Candenas, ML. mRNA expression of tachykinins and tachykinin receptors in different human tissues. Eur J Pharmacol. 2004;494 (2-3):233-239.

8. Von Euler US, Gaddum JH. An unidentified depressor substance in certain tissue extracts. J Physiol (Lond). 1931;72(1):74-87.

9. Chang MM, Leeman SE, Niall HD. Amino acid sequence of substance P. Nature. 1971;232(29):86-87.

10. Kimura S, Okada M, Sugita Y, Kanazawa I, Munekata E. Novel Neuropeptides, Neurokinin $\alpha$ and $\beta$, Isolated from Porcine Spinal Cord. Proc Jpn Acad. 1983;(59):101-104.

11. Kangawa K, Minamino N, Fukuda A, Matsuo H. Neuromedin K: a novel mammalian tachykinin identified in porcine spinal cord. Biochem Biophys Res Commun. 1983;114(2):533-540.

12. Nawa H, Doteuchi M, Igano K, Inouye K, Nakanishi S. Substance K: a novel mammalian tachykinin that differs from substance $\mathrm{P}$ in its pharmacological profile. Life Sci. 1984;34(12):1153-1160.

13. Liu K, Castillo MD, Murthy RG, Patel N, Rameshwar P. Tachykinins and hematopoiesis. Clin Chim Acta. 2007;385(1-2):28-34.

14. Page NM. Hemokinins and endokinins. Cell Mol Life Sci. 2004;61(13):1652-1663.

15. Almeida TA, Rojo J, Nieto PM, Pinto FM, et al. Tachykinins and tachykinin receptors: structure and activity relationships. Curr Med Chem. 2004;11(15):2045-2081.

16. MacDonald MR, McCourt DW, Krause JE. Posttranslational processing of alpha-, beta-, and gamma-preprotachykinins. Cell-free translation and early posttranslational processing events. J Biol Chem 1988;263(29):15176-15183.

17. Eipper BA, Stoffers DA, Mains RE. The biosynthesis of neuropeptides: peptide alpha-amidation. Annu Rev Neurosci. 1992;(15):57-85.

18. Joshi DD, Dang A, Yadav P, et al. Negative feedback on the effects of stem cell factor on hematopoiesis is partly mediated through neutral endopeptidase activity on substance P: a combined functional and proteomic study. Blood. 2001;98(9):2697-2706.

19. Klassert TE, Pinto F, Hernández M, et al. Differential expression of neurokinin B and hemokinin-1 in human immune cells. J Neuroimmunol. 2008;196(1-2):27-34.

20. Zhang Y, Berger A, Milne CD, Paige CJ. Tachykinins in the immune system. Curr Drug Targets. 2006;7(8):1011-1020.

21. Chavolla-Calderón M, Bayer MK, Fontán JJ. Bone marrow transplantation reveals an essential synergy between neuronal and hemopoietic cell neurokinin production in pulmonary inflammation. J Clin Invest. 2003;111(7):973-980.

22. Page NM, Bell NJ, Gardiner S, et al. Characterization of the endokinins: human tachykinins with cardiovascular activity. Proc Natl Acad Sci US A. 2003;100(10):6245-6250.

23. Ho WZ, Douglas SD. Substance P and neurokinin-1 receptor modulation of HIV. J Neuroimmunol. 2004;157(1-2):48-55

24. Nowicki M, Ostalska-Nowicka D, Kondraciuk B, Miskowiak B. The significance of substance $\mathrm{P}$ in physiological and malignant haematopoiesis. J Clin Pathol. 2007;60(7):749-755.

25. Sudakov SK, Medvedeva OF, Rusakova IV, Terebilina NN, Goldberg SR. Differences in genetic predisposition to high anxiety in two inbred rat strains: role of substance P, diazepam binding inhibitor fragment and neuropeptide Y. Psychopharmacol. 2001;154(4):327-335.

26. Stockmeier CA, Shi X, Konick L, et al. Neurokinin-1 receptors are decreased in major depressive disorder. Neuroreport. 2002;13(9):1223-1227.

27. Rioux L, Joyce JN. Substance P receptors are differentially affected in Parkinson's and Alzheimer's disease. J Neural Transm Park Dis Dement Sect. 1993;6(3):199-210.
28. Vink R, Nimmo AJ, Cernak I. An overview of new and novel pharmacotherapies for use in traumatic brain injury. Clin Exp Pharmacol Physiol. 2001;28(11):919-921.

29. Stumm R, Culmsee C, Schafer MK, Krieglstein J, Weihe E. Adaptive plasticity in tachykinin and tachykinin receptor expression after focal cerebral ischemia is differentially linked to gabaergic and glutamatergic cerebrocortical circuits and cerebrovenular endothelium. J Neurosci. 2001;21(3):798-811.

30. Liu H, Sankar R, Shin DH, Mazarati AM, Wasterlain CG. Patterns of status epilepticus-induced substance $\mathrm{P}$ expression during development. Neuroscience. 2000;101(2):297-304.

31. Gerard NP, Bao L, Xiao-Ping H, Gerard C. Molecular aspects of the tachykinin receptors. Regul Pept. 1993;43(1-2):21-35.

32. Attwood TK. A compendium of specific motifs for diagnosing GPCR subtypes. Trends Pharmacol Sci. 2001;22(6):162-165.

33. Maggi CA. The mammalian tachykinin receptors. General Pharmacol. 1995;26(5):911-944.

34. Pennefather JN, Lecci A, Candenas ML, Patak E, Pinto FM, Maggi CA. Tachykinins and tachykinin receptors: a growing family. Life Sci. 2004;74(12):1445-1463.

35. Ramkissoon SH, Patel HJ, Taborga M, Rameshwar P. G protein-coupled receptors in haematopoietic disruption. Expert Opin Biol Ther. 2006;6(2):109-120.

36. Fong TM, Anderson SA, Yu H, Huang RRC, Strader CD. Differential activation of intracellular effector by two isoforms of human neurokinin-1 receptor. Mol Pharmacol. 1992;41(1):24-30.

37. Lai JP, Lai S, Tuluc F, et al. Differences in the length of the carboxyl terminus mediate functional properties of neurokinin-1 receptor. Proc Natl Acad Sci U S A. 2008;105(34):12605-12610.

38. Tuluc F, Lai JP, Kilpatrick LE, Evans DL, Douglas SD. Neurokinin 1 receptor isoforms and the control of innate immunity. Trends Immunol. 2009;30(6):271-276.

39. Douglas SD, Lai JP, Tuluc F, Schwartz L, Kilpatrick LE. Neurokinin-1 receptor expression and function in human macrophages and brain Perspective on the role in HIV neuropathogenesis. Ann NY Acad Sci. 2008;1144(1):90-96.

40. Grant AD, Akhtar R, Gerard NP, Brain SD. Neurokinin B induces oedema formation in mouse lung via tachykinin receptor-independent mechanisms. J Physiol. 2002;543(3):1007-1114.

41. Bandari PS, Qian J, Oh HS, et al. Crosstalk between neurokinin receptors is relevant to hematopoietic regulation: cloning and characterization of neurokinin-2 promoter. J Neuroimmunol. 2003;138(1-2): 65-75.

42. Quartara L, Maggi CA.The tac hykinin NK1 receptor Part I: ligands and mechanisms of cellular activation. Neuropeptides. 1997;31(6): 537-563.

43. Valant C, Maillet E, Bourguignon JJ, et al. Allosteric functional switch of neurokinin A-mediated signaling at the neurokinin NK2 receptor: structural exploration. J Med Chem. 2009;52(19):5999-6011.

44. Palanche T, Ilien B, Zoffmann S, et al. The neurokinin A receptor activates calcium and cAMP responses through distinct conformational states. J Biol Chem. 2001;276(37):34853-34861.

45. Williams R, Zou X, Hoyle GW. Tachykinin-1 receptor stimulates proinflammatory gene expression in lung epithelial cells through activation of NF-kappaB via a G(q)-dependent pathway. Am J Physiol Lung Cell Mol Physiol. 2007;292(2):430-437.

46. Krause JE, Bu JY, Takeda Y, et al. Structure, expression and second messenger-mediated regulation of the human and rat substance $\mathrm{P}$ receptors and their genes. Regul Pept. 1993;46(1-2):59-66.

47. Janelsins BM, Mathers AR, Tkacheva OA, et al. Proinflammatory tachykinins that signal through the neurokinin 1 receptor promote survival of dendritic cells and potent cellular immunity. Blood. 2009;113(13):3017-3026.

48. Corcoran KE, Rameshwar P. Nuclear factor-kappaB accounts for the repressor effects of high stromal cell-derived factor-1alpha levels on Tac1 expression in nontumorigenic breast cells. Mol Cancer Res. 2007a;5(4):373-381. 
49. Jorgensen R, Holliday ND, Hansen JL, et al. Characterization of G-protein coupled receptor kinase interaction with the neurokinin-1 receptor using bioluminescence resonance energy transfer. Mol Pharmacol. 2008;73(2):349-358.

50. Luttrell LM, Lefkowitz RJ. The role of beta-arrestins in the termination and transduction of G-protein-coupled receptor signals. J Cell Sci. 2002;115(Pt 3):455-465.

51. Bennett VJ, Perrine SA, Simmons MA. Neurokinin-1 receptor resensitization precedes receptor recycling. J Pharmacol Exp Ther. 2005;313(3): $1347-1354$

52. Cottrell GS, Padilla B, Pikios S, et al. Ubiquitin-dependent down-regulation of the neurokinin-1 receptor. J Biol Chem. 2006;281(38): 27773-27783

53. Vauquelin G, Van Liefde I. G protein-coupled receptors: a count of 1001 conformations. Fundam Clin Pharmacol. 2005;19(1):45-56.

54. Hastrup H, Schwartz TW. Septide and neurokinin A are high affinity ligands on the NK-1 receptor: evidence from homologous versus heterologous binding analysis. FEBS Lett. 1996;399(3):264-266.

55. Rameshwar P, Ganea D, Gascón P. In vitro stimulatory effect of substance P on hematopoiesis. Blood. 1993;81(2):391-398.

56. Rameshwar $P, G a s c o n ~ P$. Induction of negative hematopoietic regulators by neurokinin-A in bone marrow stroma. Blood. 1996;88(1):98-106.

57. Simmons PJ, Levesque JP, Zannettino AC. Adhesion molecules in haemopoiesis. Baillieres Clin Haematol. 1997;10(3):485-505.

58. Zon LI. Developmental biology of hematopoiesis. Blood. 1995;86(8):2876-2891.

59. Kondo M, Wagers AJ, Manz MG, et al. Biology of hematopoietic stem cells and progenitors: implications for clinical application. Annu Rev Immunol. 2003;(21):759-806.

60. Martinez-Agosto JA, Mikkola HK, Hartenstein V, Banerjee U. The hematopoietic stem cell and its niche: a comparative view. Genes Dev. 2007;21(23):3044-3060.

61. Naveiras O, Nardi V, Wenzel PL, Hauschka PV, Fahey F, Daley GQ. Bone-marrow adipocytes as negative regulators of the haematopoietic microenvironment. Nature. 2009;460(7252):259-263.

62. Sugimura R, Li L. Shifting in balance between osteogenesis and adipogenesis substantially influences hematopoiesis. J Mol Cell Biol. 2010;2(2):61-62.

63. Bianco P, Robey PG, Simmons PJ. Mesenchymal stem cells: revisiting history, concepts, and assays. Cell Stem Cell. 2008;2(4):313-319.

64. Rodríguez JP, Astudillo P, Ríos S, Pino AM. Involvement of adipogenic potential of human bone marrow mesenchymal stem cells (MSCs) in osteoporosis. Curr Stem Cell Res Ther. 2008;3(3):208-218.

65. Corcoran KE, Trzaska KA, Fernandes H, et al. Mesenchymal stem cells in early entry of breast cancer into bone marrow. PLoS One. 2008;3(6): e2563.

66. Matsuoka S, Tsuji K, Hisakawa H, et al. Generation of definitive hematopoietic stem cells from murine early yolk sac and paraaortic splanchnopleures by aorta-gonad-mesonephros region-derived stromal cells. Blood. 2001;98(1):6-12.

67. Ogawa M. Differentiation and proliferation of hematopoietic stem cells. Blood. 1993;81(11):2844-2853.

68. Müller-Sieburg CE, Deryugina E. The stromal cells' guide to the stem cell universe. Stem Cells. 1995;13(5):477-486.

69. Meunch MD, Schneider JG, Moore MAS. Interaction amongst colony stimulating factors, IL-1b, IL-6 and kit-ligand in the regulation of primitive murine hematopoietic cells. Exp Hematol. 1992;20(3):339-349.

70. Grebien F, Kerenyi MA, Kovacic B, et al. Stat5 activation enables erythropoiesis in the absence of EpoR and Jak2. Blood. 2008;111(9):4511-4522.

71. North TE, de Bruijn MF, Stacy T, et al. Runx1 expression marks long-term repopulating hematopoietic stem cells in the midgestation mouse embryo. Immunity. 2002;16(5):661-672.

72. Lapidot T, Dar A, Kollet O. How do stem cells find their way home? Blood. 2005;106(6):1901-1910.
73. Corcoran KE, Patel N, Rameshwar P. Stromal derived growth factor-1alpha: another mediator in neural-emerging immune system through Tac1 expression in bone marrow stromal cells. $J$ Immunol. 2007;178(4):2075-2082.

74. Tabarowski Z, Gibson-Berry K, Felten SY. Noradrenergic and peptidergic innervation of the mouse femur bone marrow. Acta Histochem. 1996;98(4):453-457.

75. Zhang Y, Paige CJ. T-cell developmental blockage by tachykinins antagonists and the role of hemokinin 1 in T lymphopoiesis. Blood. 2003;102(6):2165-2172.

76. Tsuda T, Wong D, Dolovich J, Bienenstock J, Marshall J, Denbury JA. Synergistic effects of nerve growth factor and granulocyte-macrophage colony-stimulating factor on human basophilic cell differentiation. Blood. 1991;77(5):971-979.

77. Tordjman R, Lepelletier Y, Lemarchandel V, et al. A neuronal receptor, neuropilin-1, is essential for the initiation of the primary immune response. Nature Immunol. 2002;3(5):477-482.

78. Bischoff SC, Dahinden CA. Effect of nerve growth factor on the release of inflammatory mediators by mature human basophils. Blood. 1992;79(10):2662-2669.

79. Murthy RG, Greco SJ, Taborga M, Patel N, Rameshwar P. Tac1 regulation by RNA-binding protein and miRNA in bone marrow stroma: Implication for hematopoietic activity. Brain Behav Immun. 2008;22(4):442-450.

80. Corcoran KE, Malhotra A, Molina CA, Rameshwar P. Stromal-derived factor-1alpha induces a non-canonical pathway to activate the endocrine-linked Tac1 gene in non-tumorigenic breast cells. $J \mathrm{Mol}$ Endocrinol. 2008;40(3):113-123.

81. Singh D, Joshi DD, Hameed M, et al. Increased expression of preprotachykinin-I and neurokinin receptors in human breast cancer cells: implications for bone marrow metastasis. Proc Natl Acad Sci US A. 2000;97(1):388-393.

82. Kang HS, Trzaska KA, Corcoran K, Chang VT, Rameshwar P. Neurokinin receptors: relevance to the emerging immune system. Arch Immunol Ther Exp (Warsz). 2004;52(5):338-347.

83. Perez LE, Alpdogan O, Shieh JH, et al. Increased plasma levels of stromal-derived factor-1 (SDF-1/CXCL12) enhance human thrombopoiesis and mobilize human colony-forming cells (CFC) in NOD/SCID mice. Exp Hematol. 2004;32(3):300-307.

84. Hattori K, Heissig B, Rafii S. The regulation of hematopoietic stem cell and progenitor mobilization by chemokine SDF-1. Leuk Lymphoma. 2003;44(4):575-582.

85. Lapteva N, Yang AG, Sanders DE, Strube RW, Chen SY. CXCR4 knockdown by small interfering RNA abrogates breast tumor growth in vivo. Cancer Gene Ther. 2005;12(1):84-89.

86. Reddy BY, Greco SJ, Patel PS, Trzaska KA, Rameshwar P. RE-1-silencing transcription factor shows tumor-suppressor functions and negatively regulates the oncogenic TAC1 in breast cancer cells. Proc Natl Acad Sci U SA. 2009;106(11):4408-4413.

87. Rameshwar P, Ganea D, Gascon P. Induction of IL-3 and granulocytemacrophage colony-stimulating factor by substance $\mathrm{P}$ in bone marrow cells is partially mediated through the release of IL-I and IL-6. J Immunol. 1994;152(8):4044-4054.

88. Rameshwar P, Joshi DD, Yadav P, et al. Mimicry between neurokinin-1 and fibronectin may explain the transport and stability of increased substance P-immunoreactivity in patients with bone marrow fibrosis. Blood. 2001;97(10):3025-3031.

89. Fras C, Kravetz P, Mody DR, Heggeness MH. Substance P-containing nerves within the human vertebral body: an immunohistochemical study of the basiverterbral nerve. Spine J. 2003;3(1):63-67.

90. Goto T, Tanaka T. Tachykinins and tachykinin receptors in the bone. Microsc Res Tech. 2002;(58):91-97.

91. Rameshwar P, Gascon P. Neural regulation of hematopoiesis by the tachykinins. Mol Biol Hemat. 1996;(5):463-470.

92. Zhang Y, Lu L, Furlonger C, et al. Hemokinin is a hematopoietic specific tachykinin that regulates B lymphopoiesis. Nat Immunol. 2000;1(5):392-397. 
93. Rameshwar P, Gascon P, Ganea D. Stimulation of IL-2 production in murine lymphocytes by substance $\mathrm{P}$ and related tachykinins. J Immunol. 1993;151(5):2484-2496.

94. Rameshwar P. Substance P: a regulatory neuropeptide for hematopoiesis and immune functions. Clin Immunol Immunopathol. 1997;85(2):129-133.

95. Lotz M, Vaughan JH, Carson DA. Effect of neuropeptides on production of inflammatory cytokines by human monocytes. Science. 1988;241(4870):1218-1221.

96. Laurenzi MA, Persson MAA, Dalsgaard CJ, Haegerstrand A. The neuropeptide substance $\mathrm{P}$ stimulates production of interleukin $\mathrm{I}$ in human blood monocytes: Activated cells are preferentially influenced by the neuropeptide. Scand J Immunol. 1990;31(4):529-533.

97. Cozens PJ, Rowe FM. Substance P is a potent inducer of TNF and IL-1 secretion by macrophages. A potent role for TNF in the pathogenesis of asthma. Immunobiology. 1987;175:7-15.

98. Kimball ES, Persico FJ, Vaught JL. Substance P, neurokinin A, and neurokinin $\mathrm{B}$ induce generation of IL-I-like activity in P388D1 cells. Possible relevance to arthritic disease. J Immunol. 1988;141(10):3564-3569.

99. Wagner F, Fink R, Hart R, Dancygier H. Substance P enhances interferon- $\gamma$ production by human peripheral blood mononuclear cells. Regul Pept. 1987;19(5-6):355-364.

100. Rameshwar P, Gascon P, Ganea D. Immunoregulatory effects of neuropeptides Stimulation of interleukin-2 production by Substance P. J Neuroimmunol. 1992;37(1-2):65-74.

101. Ansel JC, Brown JR, Payan DG, Brown MA. Substance P selectively activates TNF- $\alpha$ gene expression in murine mast cells. $J$ Immunol. 1993; 150(10):4478-4485.

102. Rameshwar P, Gascon P. Substance P (SP) mediates production of stem cell factor and interleukin-1 in bone marrow stroma: Potential autoregulatory role for these cytokines in SP receptor expression and induction. Blood. 1995;86(2):482-490.

103. Vishalakumar S, Patel H, Moharita AL, Harrison JS, Rameshwar P. The anti-proliferative effect of neurokinin-A on hematopoietic progenitor cells is partly mediated by p53 activating the 5 ' flanking region of neurokinin-2 receptor. Cell Signal. 2006;18(4):422-432.
104. Ricardo M, Trzaska KA, Rameshwar P. Neurokinin-A inhibits cell cycle activators in K562 cells and activates Smad 4 through a noncanonical pathway: a novel method in neural-hematopoietic axis. J Neuroimmunol. 2008;204(1-2):85-91.

105. Bandari PS, Qian J, Yehia G, et al. Differences in the expression of neurokinin receptor in neural and bone marrow mesenchymal cells: implications for neuronal expansion from bone marrow cells. Neuropeptides. 2001;36(1):13-21.

106. Simeonidis S, Castagliuolo I, Pan A, et al. Regulation of the NK-1 receptor gene expression in human macrophage cells via an NF- $\mathrm{KB}$ site on its promoter. Proc Natl Acad Sci US A. 2003;100(5):2957-2962.

107. Vazquez-Prado J, Casas-Gonzalez P, Garcia-Sainz JA. G protein-coupled receptor cross-talk: pivotal roles of protein phosphorylation and protein-protein interactions. Cell Signal. 2003;15(6):549-557.

108. Yoshikawa T, Kanazawa H. Functional crosstalk between $\beta_{2}$-adrenoreceptor and muscarinic acetylcholine receptor: implications for gene-gene interactions and bronchodilatory responses in patients with asthma and COPD. Curr Pharmacogen Pers Med. 2008;6(4):302-319.

109. Sun J, Ramnath RD, Tamizhselvi R, Bhatia M. Role of protein kinase $\mathrm{C}$ and phosphoinositide 3-kinase-Akt in substance P-induced proinflammatory pathways in mouse macrophages. FASEB J. 2009;23(4):997-1010.

110. Sassone-Corsi P. Transcription factors responsive to cAMP. Annu Rev Cell Dev Biol. 1995;(11):355-377.

111. Barnes PJ. Receptor heterodimerization: a new level of cross-talk. J Clin Invest. 2006;116(5):1210-1212.

112. Greco SJ, Smirnov SV, Murthy RG, Rameshwar P. Synergy between the RE-1 silencer of transcription and NFkappaB in the repression of the neurotransmitter gene TAC1 in human mesenchymal stem cells. J Biol Chem. 2007;282(41):30039-30050.

113. Rameshwar P, Gascon P, Bandari PS, Joshi DD, Fernandes A, Dang A. Structural similarity between the bone marrow extracellular matrix protein and neurokinin 1 could be the limiting factor in the hematopoietic effects of substance P. Can J Pharmacol Physiol. 2002;80(5):475-481.

\section{Publish your work in this journal}

The Journal of Receptor, Ligand and Channel Research is an international, peer-reviewed, open access, online journal. The journal welcomes laboratory and clinical findings in the fields of biological receptors, ligands, channel and signal transduction research including: receptors and signalling; ligands; transporters, pores and channels; binding and activation; receptor

\section{Dovepress}

regulation; role of receptors in diseases and their treatment; molecular basis of membrane structure and functions; molecular models of membranes. The manuscript management system is completely online and includes a very quick and fair peer-review system. Visit http://www.dovepress.com/ testimonials.php to read real quotes from published authors. 